\title{
THE
}

\section{Alternate Conceptions of Preservice Elementary Teachers: The Itakura Method}

Aaron D. Isabelle

Cornelis de Groot

University of Rhode Island, degrootc@uri.edu

Follow this and additional works at: https://digitalcommons.uri.edu/education_facpubs

Terms of Use

All rights reserved under copyright.

\section{Citation/Publisher Attribution}

Isabelle, Aaron D., and Cornelis de Groot. "Alternate Conceptions of Pre-service Elementary Teachers: The Itakura Method." Journal for Science Teacher Education, vol. 19, no. 5, 2008, pp. 417-435. doi: 10.1080/ 10476210600680416

Available at: http://dx.doi.org/10.1007/s10972-008-9105-8

This Article is brought to you for free and open access by the School of Education at DigitalCommons@URI. It has been accepted for inclusion in School of Education Faculty Publications by an authorized administrator of DigitalCommons@URI. For more information, please contact digitalcommons-group@uri.edu. 


\section{Alternate Conceptions of Pre-service Elementary Teachers: The Itakura Method}

\section{Introduction and Purpose}

The purpose of this study was to determine the effectiveness of the inquiry-based Itakura Method (Itakura, 1967) in altering pre-service teachers' alternate conceptions with regard to the concept of the expansion of a solid due to heating, as well as the strength of the method over time. Our study intends to answer the following questions: Is the use of the Itakura Method an effective strategy for revealing pre-service teacher alternate conceptions? Does the Itakura Method have an immediate effect on pre-service teacher learning of a science concept? Does the Itakura Method exhibit strength over time with regard to mediating pre-service teachers' alternate conceptions?

The Itakura Method is one of a number of inquiry-based teaching methods that are utilized in the course, "Connecting Math, Science, and Technology in the Elementary School," in the Department of Elementary Education at the State University of New York at New Paltz. The focus of the Itakura Method is peer discourse; that is, students share their ideas, question one another, and debate as they struggle to negotiate meaning about a science or math concept. This approach is used to provide a method that has the potential of mediating alternate conceptions in pre-service teachers. The pre-service teachers learn about the method first-hand by participating in an inquiry-based learning activity.

Although research has shown that there is limited application of this method for lower elementary grades, since young children have difficulty constructing explanations that are different from their experiences (Driver, et al. 1994; Lewis \&Linn, 1994), we feel our research shows that it has great promise for elementary pre-service and in-service teachers. The pre- 
service teachers in our study were given open-ended questions before the activity (preassessment $\mathrm{P}$, see Appendix A), right after the activity (immediate post-assessment PA0, see Appendix A) and then one, two, and three months later (post-assessment PA1, PA2, PA3, see Appendix B). Their explanations were coded according to a three level rubric of understanding; numerous alternate conceptions were revealed. Mean data and learning gains were also calculated. Using a paired sample t-test of the differences of the pre- and post-assessment mean data, the results revealed that there was not only a statistically significant increase in pre-service teacher learning after participating in the Itakura Method, but also retention levels were significant over a period of three months during the methods course.

\section{Background: Itakura Method}

The Itakura Method was proposed by Kiyonobu Itakura in 1967. This method is often referred to as the Hypothesis-Experiment-Instruction (Kasetsu-Jikken-Jiggo) or HEI method. According to Itakura (1967), "What is known to scientists is unknown to students... using this method students succeed in finding a law in the same way as scientists do." By implementing the three phases in sequence, students' ideas and naïve theories are directly confronted by the experimental result; students are guided in the development of an understanding of a particular science concept.

The Itakura Method, although similar to the Predict-Observe-Explain (POE) technique in its basic approach, is quite different in nature. The POE technique, developed by Champagne, Klopfer \& Anderson (1980), "involves students predicting the result of a demonstration and discussing the reasons for their predictions; observing the demonstration; and finally explaining any discrepancies between their predictions and observations" (Kearney \& Treagust, 2000, p. 2). 
POE is a strategy for eliciting students' ideas and also for promoting student discussion. "Since POE tasks help students explore and justify their own ideas, this strategy has been used to investigate student ideas" (Kearney \& Treagust, 2000, p. 2). By using this strategy, teachers are able to identify both students' understanding and their process skills development (Palmer, 1995). Therefore, POE is an effective diagnostic technique that has been used to identify students' knowledge and understanding of science concepts primarily though student discussion and reasoning. The Itakura Method also strongly relies upon student discourse, especially during the hypothesis and experiment phases. However, the Itakura Method is much more mediative than diagnostic in nature. The instruction phase of the Itakura method particularly aims at connecting new learning to other real world phenomena so that the learner might not revert to initial alternate conceptions. The Itakura method, therefore, has a strong didactic component to help deepen students' understanding of a particular science concept.

In the hypothesis phase, students are introduced to an experimental set-up with an unknown outcome. Simple, everyday materials are used to help make the students more comfortable with the learning situation. By using materials that they have previously come in contact with, the suspicion that there is some hidden trick in the set-up is minimized. A question is posed in the form of a hypothesis: "If I do this..., then what do you think will happen?" Three possible choices are offered to the students. (Note: presenting students with three possible choices is not an original component of the Itakura Method. We added this feature to the method because in our experiences it serves as an effective way to help the students focus their thinking.) Students can ask questions for clarification to insure that they understand all aspects of the setup, the materials being used, and how the experiment will be conducted. Students are then invited to explore the set-up to gain further clarification. Before the instructor makes a transition 
to the next phase, the students are asked to write down their individual predictions and to explain their thinking.

In the experiment phase, cooperative groups discuss their individual predictions for the outcome of the experiment and their reasons why. This is when students are engaged in active discussion and explore one another's thinking through discourse. It is the goal of the whole group to try to come to a consensus through discussion and debate. The various groups share their ideas with the whole class. Students vote on the outcome and the teacher tallies the votes. The experiment is performed.

Finally in the instruction phase, the instructor guides the students away from focusing on who predicted correctly or incorrectly to an emphasis on the explanation of what happened in the experiment. Through scaffolding, the scientific concept is related to other, more familiar, realworld phenomena that exhibit the same underlying principle.

\section{Guiding Literature}

Alternate conceptions are commonly defined as "preconceptions or models that have the potential to interfere with future learning" (Klammer, 1998, p. 4). Students' alternate conceptions about science concepts have been well documented in a range of studies. Some studies show that "children bring to science lessons views of the world and meanings which have a significant impact on learning" (Osborne \& Freyberg, 1994, p. 1). Other studies show the persistence of such alternate conceptions. For example, Klammer (1998, p. 5) states, “Analysis of errors on qualitative tests along with interview data suggests that students are not simply failing to learn new material, but are maintaining alternative frameworks that are preventing the integration and acceptance of new concepts.” Osborne and Freyberg (1994, p. 13) assert that 
"alternate conceptions derive from the process of meaning making whereby individuals naturally attempt to make sense of the world in which they live in terms of their experiences and their current knowledge." Some research programs in the area of physics education in the early 1980's (Chi, Feltovich, \& Glaser, 1981; Larkin, 1983) focused on "novice-expert differences" in terms of knowledge structures and reasoning to explain the cause of alternate conceptions. Novice thinking, characterized as "concrete," resulted in "over generalized applications of prior knowledge." The thinking of science experts on the other hand, characterized as "abstract," enabled the individual to "transform a wide range of problematic situations into a smaller number of more familiar and unproblematic ones" (Smith, DiSessa, \& Roschelle, 1993, p. 141). This idea of knowledge structures was furthered by Perkins (1992) who described "fragile knowledge" as a combination or interaction of different types of knowledge in a learner including "missing knowledge," "inert knowledge," "naïve knowledge," and "ritual knowledge." Perkins used the term "naïve knowledge" to refer to "alternate conceptions," which, according to Klammer (1998, p. 8), "can result from the failure of the curriculum to directly address the misconceptions or to view them as unworthy of consideration."

Alternate conceptions research has been heavily influenced by the conceptual change literature (Watson, 1994; Smith; 1990; Smith \& Anderson, 1984; Stofflett, 1994; Rowe, 1990). The Conceptual Change Model (CCM), developed by Posner, Strike, Hewson and Gerzog (1982), explains how an individual's existing conceptions change when confronted by a new conception. Thomas Kuhn (1970), among other historians and philosophers of science, significantly influenced the Conceptual Change Model by comparing individual learning to learning within scientific communities. According to CCM, individual learning is similar to construction of knowledge in scientific communities characterized by shifts from one 
paradigm/theory to another, as well as the occurrence of anomalies which can subvert the existing tradition of scientific practice. Specifically, four conditions need to be met before conceptual change can take place: 1) the learner must be dissatisfied with the existing conception, 2) a new conception must be intelligible, 3) a new conception must be plausible, and 4) a new conception must be fruitful. These conditions apply both to the learners' already existing conceptions and to the new conception that is considered (Posner, Strike, Hewson \& Gerzog, 1982). Another aspect of CCM is referred to as the learner's "conceptual ecology," which incorporates different kinds of knowledge that the learner holds, such as anomalies, analogies, and beliefs. The learner's conceptual ecology provides the context in which conceptual change can occur.

Hewson and Thorley (1989) extended CCM by establishing the idea of "status" of a particular conception. They defined status as "the extent to which the conception is intelligible, plausible, and fruitful. They claimed that conceptual change is about raising and lowering the status of the conditions. Learning a new conception means that its status rises" (Yuruk, Ozdemir $\&$ Beeth, 2003, p. 6). The role of the teacher in facilitating this approach to conceptual change requires that the teacher provide metacognitive tools, such as intelligibility and plausibility, during instruction and that students learn to apply these tools when discussing science concepts (Beeth, 1998). In the early 1990s, Strike and Posner (1992) revisited their initial CCM and developed the Revisionist Concept Change Model. They concluded that the initial CCM "must be more dynamic and developmental, emphasizing the shifting patterns of mutual influence between the various components of an evolving conceptual ecology" (p. 163). In essence, the affective and social aspects of a learner were taken into consideration in addition to epistemological concerns. In sum, this research emphasizes confronting, challenging, and 
replacing the learner's alternate conceptions since the potential for future learning is threatened when newly learned information links to those preconceptions (Duschl, 1990).

In a more current model, Vosniadou and her colleagues (2001) propose that conceptual change can occur through a process of active knowledge acquisition in which the learner builds on existing knowledge; that is, children's initial conceptual knowledge about the physical world is organized in an initial framework which provides the foundation upon which further knowledge is constructed. In this model, alternate conceptions are viewed as mental or synthetic models that develop when children attempt to synthesize fundamentally inconsistent and conflicting information (Vosniadou \& Brewer, 1992; Vosniadou, Skopeliti, \& Ikospentaki, 2004). From this perspective, conceptual change is a slow process which involves children's gradual suspension and revision of their presuppositions. This model is fundamentally different from previous conceptual change models in that it involves building on existing knowledge, not confronting and replacing it (Vosniadou, Ioannides, Dimitrakopoulou, \& Papademetriou, 2001).

Pre-service and in-service teachers often harbor alternate conceptions and then pass on these naïve or "folk" theories regarding particular science concepts to their students. Recent research suggests that many alternate conceptions originate in the classroom and that pre-service elementary education teachers have many of the same misconceptions that their future students will have (Schoon, 1995; Jarvis, Pell \& McKeon, 2003; Khalid, 2001; Lindgren 2003; Trundle, Atwood \& Christopher, 2002; Lewis \& Linn, 1994). Some research has shown that students' and teachers' prior experiences and self-efficacy, which are linked to alternate conceptions, often block their consideration of new information (Sewell, 2002; Schoon \& Boone, 1998). Other research studies have shown that teachers will need ongoing support in maintaining the newer, scientifically correct conceptions (Jarvis et al., 2003). While there is a body of knowledge that 
assists with the remediation of alternate conceptions, there is little known about the strength of these strategies over time. The research is somewhat scant in this area, but a few studies investigate longitudinal effects of methods that remediate alternate conceptions (Greenwood \& Scribner-MacLean, 1997; Tytler, 1998; Georghiades, 2000; Trundle, Atwood, \& Christopher, 2007). This is an area that needs more research and has been incorporated in the design of our research.

In our study we investigated the immediate and the one-, two-, and three-month effects of providing viable alternative theories for alternate conceptions in elementary pre-service teachers. We used the Itakura Method for this purpose. Although research has shown that there is limited application of the Itakura Method for lower elementary grades (Driver, et al. 1994; Lewis \&Linn, 1994), our study indicates that elementary pre-service teachers can benefit from the use of this method. Research is pointing toward inquiry-based methods that incorporate strong discursive elements to alleviate the persistence of misconceptions in both teachers and their students (Jarvis et al., 2003; Taber, 2003; Hsi, 1997; Sewell, 2002). Science educator, Cynthia Crockett (2004, p. 35) states, “Active classroom conversations enable students and teachers to examine ideas, explore them aloud, and reason and re-reason through them. Such conversations can help teachers recognize and challenge students' misconceptions about science." Crockett goes on to state,

Teachers should encourage students to have conversations and respectful debates with one another. When we take time for discussion, we get a more thorough understanding of each student's interpretation of concepts or facts. These discussions enable us to pinpoint students' misconceptions and false ideas... and to help students begin to reformulate their ideas into something more accurate and useful (p. 35).

Similarly, Osborne and Freyberg (1994, p. 135) conclude from their research program that teachers need to "encourage a genuine and continuing interchange of ideas in the classroom, 
between pupil and pupil, as well as between pupil and teacher. In practice, it is only through such discourse that teachers can monitor what a child is doing and why a child thinks a particular way." Discourse, debate, and discussion, which have proven to be effective strategies for revealing and negotiating alternate conceptions with elementary students, are similarly used in our research study with pre-service elementary teachers through the Itakura Method.

Alternate conceptions have been studied and documented in virtually every domain of science. Operation Physics (1998) has compiled a comprehensive list of "children's misconceptions about science" on the web site: http://www.amasci.com/miscon/opphys.html. The list of topics covers astronomy and space science including the solar system, stars, and gravity; earth science including the Earth's atmosphere, biosphere and lithosphere, and the seasons; measurement including density; and physical sciences including energy, force and motion, heat and temperature, light and color, matter, sound, and electricity and magnetism. Osborne and Freyberg's research program (1994) investigated alternate conceptions in the physical sciences, including concepts such as light, electricity, and force and motion, as well as student ideas in the life sciences including the classification of plants and animals. More recent research programs have studied pre-service teachers' conceptions of moon phases, rock formation, photosynthesis and inheritance, the greenhouse effect, ozone layer depletion, and acid rain (Trundle, Atwood, \& Christopher, 2002; Kusnick, 2002; Cakiroglu \& Boone, 2001; Khalid, 2001).

The scientific concept under investigation in our study, the expansion of solids due to heating, has not been extensively studied for possible student alternate conceptions. Student alternate conceptions of the kinetic theory of matter (which has conceptual underpinnings for our topic) have been the subject of a recent research program (Crespo \& Pozo, 2004, p. 1342). An 
interesting finding of this study is that, "students (in grades 7-12) may assume the existence of particles and even attribute to them some of the properties recognized by chemists, but they fail to make these properties compatible with the observed reality. Thus, they fail to interpret the sensorial world with the microscopic terms." Specifically, in tasks involving expansion, students in Crespo and Pozo's study, "assumed that particles expand because the observable matter expands" (p. 1341). Thus, "when an iron bar expands, they assumed that the particles of iron grew in size" (p. 1328). Although the pre-service teachers in our study did not hold this particular alternate conception, the overall findings of this study may help to explain the difficulty that the pre-service teachers initially had with trying to explain the expansion of a solid material due to heating. That is, "students often fail to differentiate between the represented macroscopic reality and the kinetic/molecular model that it represents" (p. 1341). Various preservice teachers' alternate conceptions about the expansion of solids due to heating are recorded in the "data collection/analysis" section.

\section{Research Orientation/Method}

In the education methods class, "Connecting Math, Science, and Technology in the Elementary School," participants from three pre-service course sections, two undergraduate sections $(\mathrm{n}=26)$ and one graduate section $(\mathrm{n}=12)$, were introduced to the Itakura Method through in-class modeling. The participants were presented with an experimental set-up designed to illustrate the concept of expansion of a solid due to heating.

In the hypothesis phase, the experimental set-up was presented to the participants in the following manner: A metal rod is placed across two bricks. One end is secured while the other end rests upon a needle attached to a straw. Four unlit votive candles are placed underneath the 
rod. Participants were then allowed to closely investigate the experimental set-up and ask further questions for clarification. A few students hesitantly approached the set-up at the front of the room to get a closer look, while others picked up the metal rod and handled the materials. They were also given a picture of the set-up as shown in Figure 1 (Mysteries of Science: Expansion and Contraction - A Review, 2005).

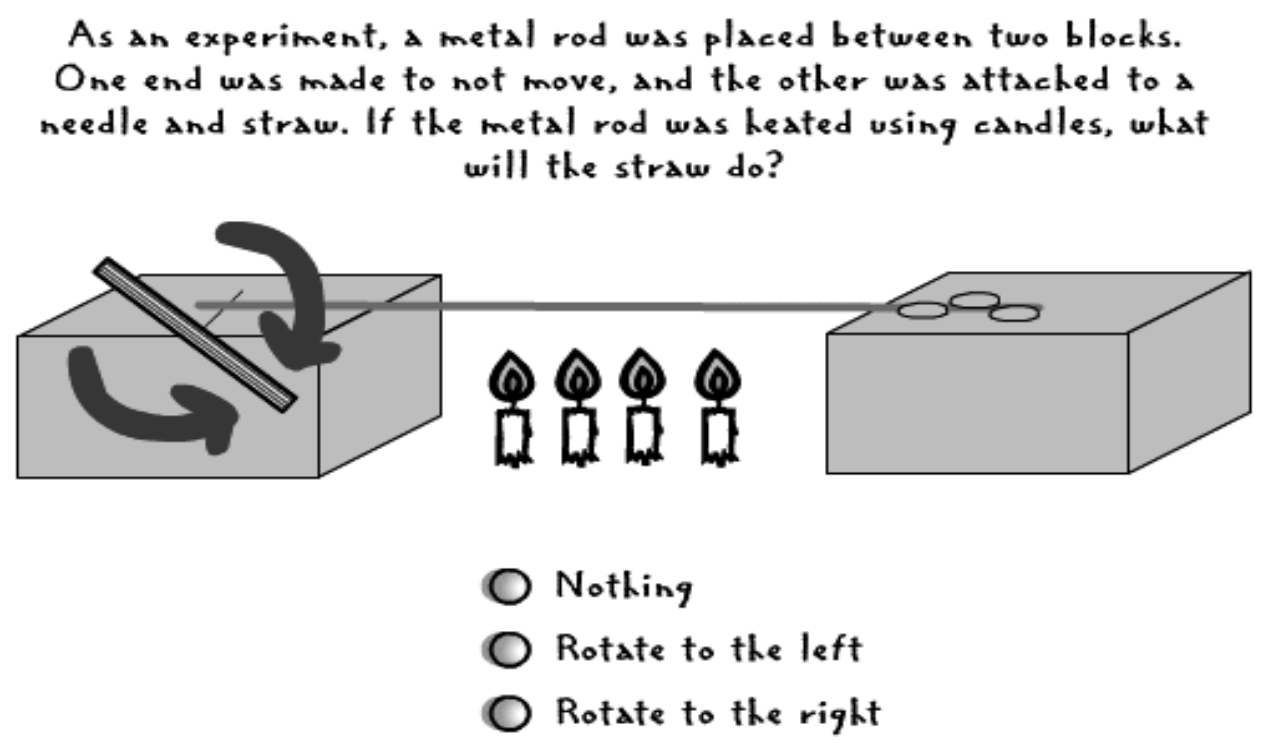

Figure 1.

Experimental set-up designed to illustrate the concept of expansion of a solid due to heating.

Next, a question was posed to them in the form of a hypothesis: "If I light the votive candles, then what should happen to the straw?" To help focus their thinking, the participants were offered three possible choices with regard to the movement of the straw: a) no motion at all, b) counterclockwise motion (rotation to the left), or c) clockwise motion (rotation to the right). Participants were asked to write down their individual predictions and to explain their thinking.

In the experiment phase, the participants were organized into small, cooperative groups. The participants shared their ideas and to try to come to a group consensus about the outcome of 
the experiment. A high level of interaction and rich discussion among the participants within each group was observed. Through discourse, the participants struggled with a variety of ideas and questions in an attempt to arrive at a consensus. After approximately ten minutes, each group was asked to report back to the class. We observed a high level of anticipation among the participants with regard to the outcome of the experiment; the classroom was completely silent when we finally conducted the experiment. As the straw began to move counterclockwise, the classroom once again filled with discussion and questions about why the straw moved.

In the instruction phase, the instructor guided the class in making connections to realworld examples, which were conceptually related to the idea underlying the experimental set-up. The strategy in this situation was to first guide participants' thinking from an understanding of the expansion of gases due to heating, then to liquids, and finally to solids. The participants were asked to think about a partially deflated basketball and how it inflates as it absorbs heat energy from the sun. The expansion of the gas inside the basketball was discussed. Then the participants were asked to think about alcohol (or mercury) in the bulb of a thermometer as it rises with increasing temperature. The expansion of the liquid as it absorbs heat energy was discussed. Lastly, the participants viewed photos of a steel bridge girder attached to an expansion joint before and after expansion due to changes in air temperature. The conceptual relationship between the expansion of the metal rod in the experimental set-up and the metal bridge girder was made explicit. Other familiar phenomena discussed included expansion joints on bridge road surfaces, expansion gaps on concrete sidewalks, and the expansion and contraction of rocks due to heating and cooling as a cause of weathering. 


\section{Data Collection/Analysis}

After the participants explored the experimental set-up in the hypothesis phase, they were asked to individually write down their predictions and explanations (pre-assessment, $P$ ). After the instruction phase, participants were asked to write down what happened in the experiment and why (immediate post-assessment, $P A 0)$. One month later, the participants were asked to recall the experimental set-up, revisit their ideas, and write down their explanations (one-month post-assessment, PA1). Two months later, the participants revisited their ideas and wrote down their explanations (two-month post-assessment, PA2). Finally, three months later, the participants revisited their ideas and wrote down their explanations once again (three-month post-assessment, PA3). During the post-assessments, the participants were given the same picture (see Figure 1) of the experimental set-up to help prompt their thinking. However, they were not given additional instruction, nor did they discuss their ideas with other participants.

Participants' explanations were coded according to a three-level rubric: 0,1 , and 2 with 0 as the lowest. At an explanation level of two (2), the pre-service teacher has a good understanding that heat conduction results in the expansion of the metal object; he/she connects heat conduction with expansion and/or emphasizes that the metal rod expands causing the pin to roll thereby moving the straw. This is a scientifically correct explanation. (Note: at this explanation level, the participant does not mention "convection" as a cause of the movement of the straw which is scientifically incorrect.) Participant responses included:

- When heated by the votive candles, the molecules in the metal rod start to vibrate. The rod expands moving over the top of the pin causing the pin to roll. As the pin rolls, the straw moves with it. 
- When the bar heats-up, it will cause the pin to rotate because heat will expand the bar which turns the pin.

At an explanation level of one (1), the pre-service teacher demonstrates some understanding of conduction, but explains that the straw moves due to some combination of conduction and convection which is not a scientifically correct explanation for the movement of the straw; he /she emphasizes conduction without making reference to the rod expanding; he/she emphasizes expansion by focusing on the molecules in the rod moving. Participant responses included:

- Conduction of heat through the metal rod to the pin causes the pin to heat-up which warms the air in the straw and the straw moves.

- The molecules in the rod will heat-up and then will heat the pin.

- The straw moves because of the movement of the atoms in the metal rod due to heating.

At an explanation level of zero (0), the pre-service teacher places an emphasis on convection only which is scientifically incorrect, or applies irrelevant concepts that are not related to heat expansion of solids. Participant responses included:

- The air is heated by the votive candles; as the hot air rises it moves the straw.

- The votive candles heat the air inside the straw; heat escapes upwards inside the straw.

- Because the straw is tilted, it will move.

- The straw will rotate to the left because we are in the Northern Hemisphere.

- I don't see why the straw would move. 
The pre-service teachers in this study harbored a variety of alternate conceptions related to heat expansion of solids. Participants at an explanation level of zero (0) incorrectly focused on the movement of the straw. The straw and the air inside of it were key components in their explanations of why the straw moves. Participants used a convection theory to explain what was happening to the air inside the straw. Participants at an explanation level of one (1) correctly focused on the heating of the metal; however, participants incorrectly used either a molecular theory or a convection theory to explain why the straw moves. Finally, participants at an explanation level of two (2) correctly focused on the heating of the metal rod as the cause, and the expansion of the rod as the effect. The participants understood that the straw serves as an indicator of a poorly visible expansion of a solid.

After the participants' explanations were coded using the three-level rubric, the scores were averaged for the P, PA0, PA1, PA2, and PA3 assessments. The mean data for the preservice teachers' explanations are shown in Table 1. The immediate post-assessment mean was 1.89 , which is a whole level increase from the pre-assessment mean of 0.79 . This shows that the Itakura Method was effective in helping participants to think about and explain the concept of expansion of solids due to heating in a more accurate, scientific way. The one-month postassessment mean was 1.74 , followed by a two-month post-assessment mean of 1.71 , and a threemonth post-assessment mean of 1.71. Although the post-assessment means slightly dropped with respect to the immediate post-assessment mean, the explanation level did stabilize. This shows the strength of this method over time by revealing that the majority of the pre-service teachers did not revert back to alternate conceptions after three months without additional or remedial instruction. 


\section{Table 1}

Pre- and Post-assessment Mean Data on Pre-service Teachers' Explanations of Heat Expansion Experiment

Pre-assessment (P) 0.79

Immediate post-assessment (PA0) $\quad 1.89$

One-month post-assessment (PA1) $\quad 1.74$

Two-month post-assessment (PA2) $\quad 1.71$

Three-month post-assessment (PA3) $\quad 1.71$

Note: All ratings are based on a three-level scale: 0,1 , and 2 with 0 as the lowest.

Paired sample t-tests were used to determine the quality of the difference in the means of the pre- and post-assessment data. The differences in the mean data of the pre-assessment and individual post-assessments were all statistically significant at a very high level with a p-value of less than 0.001 for all paired sample tests (See Table 2). The results reveal that there was not only a statistically significant increase in learning immediately after participating in the Itakura Method (PA0 - P), but also retention levels were significant over a period of three months. That is, there was relatively little change in the pre-service teachers' explanations over a three-month period during the methods course. 


\section{Table 2}

Paired Differences t-test of Pre- and Post-assessment Mean Data on Pre-service Teachers' Explanations of Heat Expansion Experiment

\begin{tabular}{llll} 
& $\begin{array}{l}\text { Differences } \\
\text { of means }\end{array}$ & $t$ value & $p$ value \\
\hline PA0 - P & 1.11 & 10.500 & $<0.001$ \\
PA1 - P & 0.95 & 8.910 & $<0.001$ \\
PA2 - P & 0.92 & 8.435 & $<0.001$ \\
PA3 - P & 0.92 & 8.435 & $<0.001$ \\
\hline
\end{tabular}

Note: The degree of freedom for all pairs was 37.

By further analyzing the individual pre-service teacher explanations, the detail in level gains can be examined. The following can be observed in Table 3 regarding the frequency of pre-service teachers' explanation levels. Six participants made zero explanation level gains throughout the three months. That is, one participant remained at a level 0 explanation, two participants remained at a level 1 explanation, and three participants remained at a level 2 explanation. Twenty-two participants made an explanation level gain of one. That is, these twenty-two participants went from a level 1 to a level 2 explanation. Of this group, eighteen participants maintained this explanation level for all three months. Of the remaining four participants, three reverted to a level 1 explanation after one month; only one participant reverted to a level 1 after two months. Finally, ten participants made an immediate gain of two explanation levels and went from level 0 to level 2. Of this group, seven participants maintained the explanation level throughout the three months and three participants reverted to a level 1 
explanation after one month. Figure 2 shows a graphical representation of the frequency of preservice teachers' explanation levels for the total population.

Table 3

Frequency of Pre-service Teachers 'Explanation Levels of Heat Expansion Experiment Frequencies

$\begin{array}{llllll}\text { Level } & P & \text { PA0 } & \text { PA1 } & \text { PA2 } & \text { PA3 }\end{array}$

\begin{tabular}{llllll}
\hline 0 & 11 & 1 & 1 & 1 & 1 \\
1 & 24 & 2 & 8 & 9 & 9 \\
2 & 3 & 35 & 29 & 28 & 28 \\
\hline
\end{tabular}

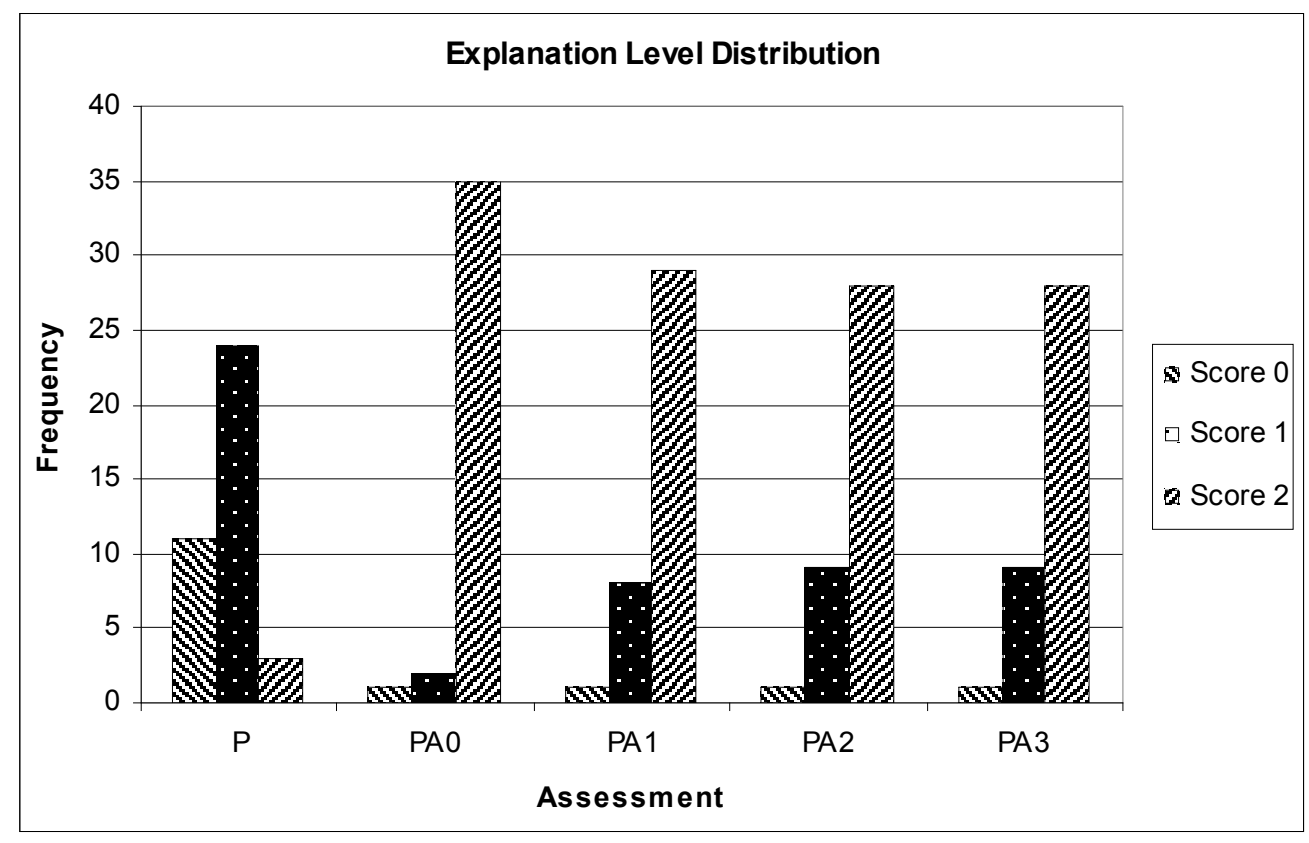

Figure 2. Frequency of Pre-Service Teachers' Explanation Levels of Heat Expansion Experiment. 
In sum, using paired sample t-tests, the differences in the pre- and post-assessment mean data revealed that there was not only a statistically significant increase in learning after participating in the Itakura Method, but also retention levels were significant over a period of three months. This study not only demonstrates that the Itakura Method has an immediate positive effect on pre-service teacher learning of a science concept, but also illustrates the strength of the Itakura Method over a three-month period of time by revealing that the majority of the pre-service teachers did not revert back to alternate conceptions over a period of three months.

\section{Discussion}

As evidenced by the ideas reported by the participants as well as the research of others, alternate conceptions can serve as obstacles to learning science concepts, and these ideas are persistent and resist change (Klammer, 1998). In our view, alternate conceptions are persistent primarily because we regard all learning as permanent. We posit that alternate conceptions and the cognitive structures associated with those conceptions are never completely eliminated even when conceptual change does occur. Therefore, it is critical that the learning of new ideas and concepts be made more attractive or more dominant than the learner's existing cognitive schema; that is, the learner's new schema must increase in "status" and be perceived by the learner as "intelligible, plausible, and fruitful" (Hewson \& Thorley, 1989). Consistent with the Revisionist Conceptual Change Model, to successfully mediate student alternate conceptions, a teaching method must first identify a learner's alternate conception, effectively help establish an attractive, alternative theory, and then assist in making the new theory useful and applicable to the learner. 
There is a real question if the efficacy of the Itakura method extends beyond the course into the elementary classrooms because, as methods instructors, we do not often know to what extent our students implement the methods that we teach them. However, we do know that many teachers teach as they were taught in their own schooling, acquiring conceptions of teaching through an "apprenticeship of observation" (Darling-Hammond \& Bransford, 2005; Goodlad, 1990; Korthagen, 2001; Lortie, 1975). The cultural scripts acquired in their early years of schooling have just as much tenacity as alternate conceptions in science. Stigler and Hiebert (1998) state that, "Teaching, like other cultural activities, is learned through informal participation over long periods of time. It is something someone learns to do by growing up in a culture rather than by formal study" (p. 6). Although we have attempted to provide dominant and powerful constructs to compete with alternate conceptions, we are faced with the task of assisting teachers to resist their own cultural scripts. Stigler and Hiebert state, "No matter how good our teachers are, they will only be as effective as the script they are using. To improve teaching over the long run, we must improve the script" $(1998$, p. 11). We believe that the methodology we have discussed in this paper has the possibility of improving the script. We suggest that this is an area of research that needs serious attention.

Linking participant learning to other related real-world examples was beneficial to both the immediate learning gain and retention for the pre-service teachers. The instructional phase of the Itakura Method is crucial in this aspect because it connects participant learning to familiar real-world phenomena which are conceptually related to the science concept underlying the experimental set-up. More scientifically accurate conceptions become more plausible as the participants' ideas are linked to a variety of recognizable contexts and examples. In connecting 
the familiar to the scientific, the participants' new ideas were able to withstand the tendency to fall back into initial alternate conceptions for the course of the semester.

This study also shows that the Itakura Method is an effective strategy in challenging preservice teachers' prior notions about a science concept to reveal their alternate conceptions. By having participants discuss and explore each other's thinking about the outcome of an experimental set-up, designed to illustrate the concept of expansion of solids due to heating, various alternate conceptions were revealed. For example, the participants' initial convection conceptions were dominant over conduction conceptions. Emphasizing the process of convection only, the participants reported that, "the air is heated by the votive candles...as the hot air rises it moves the straw," and "the votive candles heat the air inside the straw...heat escapes upwards inside the straw causing the straw to move." Other participants, who seemed to invoke various gravitational conceptions, reported that, "because the straw is tilted it will move," or "the straw will rotate to the left because we are in the Northern Hemisphere." Emphasizing some combination of the processes of conduction and convection, participants reported that, "conduction of heat through the metal rod to the pin causes the pin to heat-up which warms the air in the straw and the straw moves." Finally, some participants used a molecular theory to explain the movement of the straw stating, "The straw moves because of the movement of the atoms in the metal rod due to heating."

\section{Limitations}

In inquiry-based learning environments, novel situations and real-world tasks are often utilized to challenge students' alternate conceptions (Saxena, 1991; Liggitt-Fox, 1997). A limitation of our study, however, is that we did not put our participants in a novel situation (in 
the area of heat expansion of solids) at any of the post assessments; we relied on using the same experimental set-up. The presentation of the diagram of the experimentation set-up (Figure 1) may have triggered the proper cognitive framework at each assessment. We did not investigate this idea. Instead, our analysis was based on the rubric we developed which was very specific to the experiment at hand. Furthermore, the diagram of the experimental set-up was the only trigger; we did not allow further peer discourse, nor did we provide additional instruction in this area.

On the pre- and post-assessments, we required participant explanations of what happened in the experiment and why. Recall may have played a role in the immediate post-assessment, and possibly in the one-month assessment. However, over a period of three months, a mental reconstruction of the phenomenon would be necessary to produce a scientifically accurate explanation. A loss of participant recall may account for the slight drop in post-assessment means with respect to the immediate assessment mean. Since the participant explanation level did stabilize over a three-month period, it can be inferred that the pre-service teachers were responding and reconstructing from a relational network, rather than simply recalling from memory.

Finally, we realize that this study might have been set up with a control group. Because the Itakura Method is a required element of the aforementioned course, we could not deprive any of the students of this method. All students in the three sections of this course (including the participants in this study) learn about the Itakura Method through the exact experiential sequence described in this paper, followed by a theoretical discussion of the method's phases and instructional characteristics. We therefore decided to compare the participant group against itself over time. 


\section{Conclusion}

Using the Itakura Method in our study, we relied heavily upon the power of student discourse to help uncover participant alternate conceptions. We provided opportunities for participants to confront each others' thinking, followed by an explication of this thinking. Participants were then guided in making new and stronger connections between what they observed happen in the demonstration with other known phenomena that could be explained with the same underlying scientific principle. These familiar phenomena were introduced so that the participants would view the science concept as useful and applicable.

The data collected from this study indicates that the Itakura Method is an effective strategy in helping pre-service teachers learn a science concept. The results reveal that there was a statistically significant increase in pre-service teacher learning immediately after participating in the Itakura Method. Specifically, an immediate gain of one explanation level was made by twenty-two out of the thirty-eight participants. Ten participants made an immediate gain of two explanation levels.

With regard to the strength of the Itakura Method over time, retention levels were significant over a period of three months. That is, there was relatively little change in the preservice teachers' explanations over a three-month period during the methods course. Specifically, seven participants who made an immediate gain of two explanation levels maintained the explanation level throughout the three months. Only three participants reverted to a level one explanation after one month. Although this method was only tested within the duration of a methods course, the Itakura Method did exhibit strength over a period of three months with regard to mediating pre-service teacher alternate conceptions. 
At the heart of inquiry-based science is discourse. When scientists convey their ideas and understandings to one another within scientific communities, progress and innovation in science can occur. Similarly, in the elementary science classroom community, discourse can serve as a powerful tool to help students better understand and clarify their own ideas, as well as the ideas of others. The National Science Education Standards (NRC, 1996) state, "Science often is a collaborative endeavor, and all science depends on the ultimate sharing and debating of ideas. When carefully guided by teachers to ensure full participation by all, interactions among individuals and groups in the classroom can be vital in deepening the understanding of scientific concepts and the nature of scientific endeavors" (pp. 31-32). Strong discursive elements, therefore, should be utilized in the learning of science at all levels of instruction. The Itakura Method is one way to provide a discursive framework for students to talk their way into a deeper understanding of scientific knowledge. The results of this research are encouraging in the sample of pre-service teachers studied and are suggestive of a more generalized result well worth pursuing further. 


\section{References}

Beeth, M.E. (1998). Teaching for conceptual change: Using status as a metacognitive tool. Science Education, 82(3), 343-356

Beeth, M. E., \& Hewson, P. W. (1999). Learning goals in an exemplary science teacher's practice: Cognitive and social factors in teaching for conceptual change. Science Education, 83, 738-760.

Cakiroglu, J. \& Boone, William J. (2001). Pre-service elementary teachers' self-efficacy beliefs and their conceptions of photosynthesis and inheritance. Paper presented at the Annual Meeting of the American Educational Research Association, Seattle, Washington.

Chi, M.T.H., Feltovich, P.J., \& Glaser, R. (1981). Categorization and representation of physics problems by experts and novices. Cognitive Science, 5, 121-152.

Crespo, M.A. Gomez \& Pozo, J.I. (2004). Relationships between everyday knowledge and scientific knowledge: Understanding how matter changes. International Journal of Science Education, 26(11), 1325-1343.

Crockett, C. (2004). What do kids know and misunderstand about science? Educational Leadership, 2, 34-47.

Children's misconceptions about science. (1998). American Institute of Physics: Operation Physics. Retrieved May 15, 2005, from http://www.amasci.com/ miscon/opphys.html.

Darling-Hammond, L., \& J. Bransford (Eds.) (2005). Preparing teachers for a changing world: What teachers should learn and be able to do. San Francisco, CA: Jossey-Bass.

Driver, R. D., Asoko, H., Leach, J., Mortimer, E., \& Scott, P. (1994). Constructing scientific knowledge in the classroom. Educational Researcher, 23(7), 5-12.

Duschl, R. (1990). Restructuring science education: The importance of theories and their development. New York: Teacher's College Press.

Georghiades, P. (2000). Beyond conceptual change learning in science education: Focusing on transfer, durability, and metacognition. Educational Research, 42, 119-139.

Greenwood, A. \& Scribner-MacLean, M. (1997). Examining elementary teachers' explanations of their science content knowledge. Paper presented at the 70th Annual Meeting of the National Association for Research in Science Teaching, Oak Brook: Illinois.

Goodlad, J.I. (1990). Teachers for our nation's schools. San Francisco, CA: Jossey-Bass.

Hewson, P.W. \& Thorley, N.R. (1989). The conditions of conceptual change in the classroom. International Journal of Science Education, 11, 541-553. 
Hsi, S. (1997). Facilitating knowledge integration in science through electronic discussion: The multimedia forum kiosk. Unpublished Dissertation. University of California at Berkeley.

Itakura, Kiyonobu. (1967). Instruction and learning of concept "force" in static based on KasetsiJikken-Jiggo (Hypothesis-Experiment-Instruction): A new model of teaching science. Bulletin of National Institute for Educational Research, 52, 1-121.

Jarvis, T., Pell, A., \& McKeon, F. (2003). Changes in primary teachers' science knowledge and understanding during a two year in-service program. Research in Science and Technological Education, 21(1), 17-42.

Kearney, M., Treagust, D.F., Yeo, S. \& Zadnik, M.G. (2001). Student and teacher perceptions of the use of multimedia supported predict-observe-explain tasks to probe understanding. Research in Science Education, 31(4), 589-615.

Khalid, T. (2001). Pre-service teachers' misconceptions regarding three environmental issues. Canadian Journal of Environmental Education, 6, 102-120.

Korthagen, F. (2001). Linking practice and theory: The pedagogy of realistic teacher education. Mahwah, NJ: Lawrence Erlbaum Associates.

Kuhn, T. (1970). The structure of scientific revolutions. Chicago: University of Chicago Press.

Klammer, J. (1998). An overview of techniques for identifying, acknowledging, and overcoming alternate conceptions in physics education. 1997/98 Klingenstein Paper Project, Teacher's College, Columbia University.

Kusnick, J. (2002). Growing pebbles and conceptual prisms: Understanding the source of student misconceptions about rock formation. Journal of Geoscience Education, 50(1), 31-39.

Larkin, J.H. (1983). The role of problem representation in physics. In D.Gentner \& A.L. Stevens (Eds.), Mental Models. (pp. 75-78). Hillsdale, NJ: Lawrence Erlbaum Associates, Inc.

Lewis, E. L. \& Linn, M. C. (1994). Heat energy and temperature concepts of adolescents, adults, and experts: Implications for curricular improvements. Journal of Research in Science Teaching, 31(6), 657-677.

Liggitt-Fox, J.D. (1997). Fighting student misconceptions: Three effective strategies. Science Scope, 20(5), 28-30.

Lindgren, J. (2003). Why we have seasons and other common misconceptions. Science Scope, $26(4), 50-51$.

Lortie, D.C. (1975). Schoolteacher: A sociological study. Chicago, IL: University of Chicago Press. 
Loucks-Horsley, S., M.O. Carlson, L.H. Brink, P. Horwitz, D.P. Marsh, H. Pratt, K.R. Roy, and K. Worth. (1989). Developing and supporting teachers for elementary school science education. Andover, MA: The National Center for Improving Science Education.

Mysteries of science: Expansion and contraction - A review. (2005). Gary's Electronic Classroom: TEAMS Educational Resources. Retrieved January 06, 2005, from http://teams.lacoe.edu/documentation/classrooms/gary/heat/activities/mystery/Mystery.ht $\mathrm{ml}$.

National Research Council (NRC). (1996). National science education standards. Washington, DC: National Academy Press.

Osborne. R. \& Freyberg, P. (1994). Learning science: The implications of children's science. Portsmouth, NH: Heinemann.

Palmer, D. (1995). The POE in the primary school: An evaluation. Research in Science Education, 25(3), 323-332.

Perkins, D. (1992). Smart schools: Better thinking and learning for every child. New York: The Free Press.

Posner, G.J., Strike, K.A., Hewson, P.W., \& Gertzog, W.A. (1982). Accommodation of a scientific conception: Toward a theory of conceptual change. Science Education, 66(2), 211-227.

Rowe, M.B., Ed. (1990). What research says to the science teacher: The process of knowing. Washington, DC: National Science Teachers Association Press.

Saxena, A.B. (1991). The Understanding of the properties of light by students in India. International Journal of Science Education, 13(3), 283-289.

Schoon, K.J. (1995). The origin and extent of alternative conceptions in the earth and space sciences: A survey of pre-service elementary teachers. Journal of Elementary Science Education, 7(2), 27-46.

Schoon, K.J., \& Boone, W.J. (1998). Self-efficacy and alternative conceptions of science of preservice elementary teachers. Science Education, 82(5), 553-68.

Sewell, A. (2002). Constructivism and student misconceptions: Why every teacher needs to know about them. Australian Science Teachers' Journal, 48(4), 24-28.

Smith, E.L. (1990). A conceptual change model of learning science. In S. Glynn, R. Yeany \& B. Britton (Eds.), Psychology of the learning science (pp. 43-63). Hillsdale, NJ: Lawrence Erlbaum. 
Smith, E.L. \& Anderson, C.W. (1984). Plants as producers: A case study of elementary science teaching. Journal of Research in Science Teaching, 21(7), 685-698.

Smith, J.P, DiSessa, A., \& Roschelle, J. (1993). Misconceptions reconceived: A constructivist analysis of knowledge in transition. The Journal of the Learning Sciences, 3(2), 115-163.

Stofflett, R.T. (1994). Conceptual change in elementary school teacher candidate knowledge of rock-cycle processes. Journal of Geological Education, 42(5), 494-500.

Stigler, W.J., and J. Hiebert (1998). Teaching is a cultural activity. American Educator, 22(4), 411. Washington, DC: American Federation of Teachers

Strike, K.A. \& Posner, G.J. (1992). A revisionist theory of conceptual change. In R. Duschl \& R. Hilton (Eds.), Philosophy of science, cognitive psychology, and educational theory and practice (pp. 147-176). Albany, NY: SUNY Press.

Trundle, K.C., Atwood, R.K., \& Christopher, J.E. (2002). Pre-service elementary teachers' conceptions of moon phases before and after instruction. Journal of Research in Science Teaching, 39(7), 633-58.

Trundle, K. C., Atwood, R. K., \& Christopher, J. E. (2007). A longitudinal study of conceptual change: Preservice elementary teachers' conceptions of moon phases. Journal of Research in Science Teaching, 44(2), 303-326.

Tytler, R. (1998). Children's conceptions of air pressure: Exploring the nature of conceptual change. International Journal of Science Education, 20, 929-958.

Vosnaidou, S. \& Brewer, W.F. (1992). Mental model of the Earth: A study of conceptual change in childhood. Cognitive Psychology, 24, 535-585.

Vosniadou, S., Ioannides, C., Dimitrakopoulou, A., \& Papademetriou, E. (2001). Designing learning environments to promote conceptual change in science. Learning and Instruction, 11, 381-419.

Vosniadou, S., Skopeliti, I., Ikospentaki, K. (2004). Modes of knowing and ways of reasoning in elementary astronomy. Cognitive Development, 19(2), 203-222.

Watson, B. (1994). Switch off kids' science misconceptions. Learning, 22(5), 74-76.

Yuruk, N., Ozdemir, O. \& Beeth, M.E. (2003). The role of metacognition in facilitating conceptual change. Paper presented at the Annual Meeting of the National Association for Research in Science Teaching, Philadelphia, PA. 
Appendix A: Pre-Assessment (P) and Immediate Post-assessment (PA0)

\section{PRIOR TO THE DEMONSTRATION:}

As an experiment, a metal rod was placed between two blocks. One end was made to not move, and the other was attached to a needle and straw. If the metal rod was heated using candles, what will the straw do?

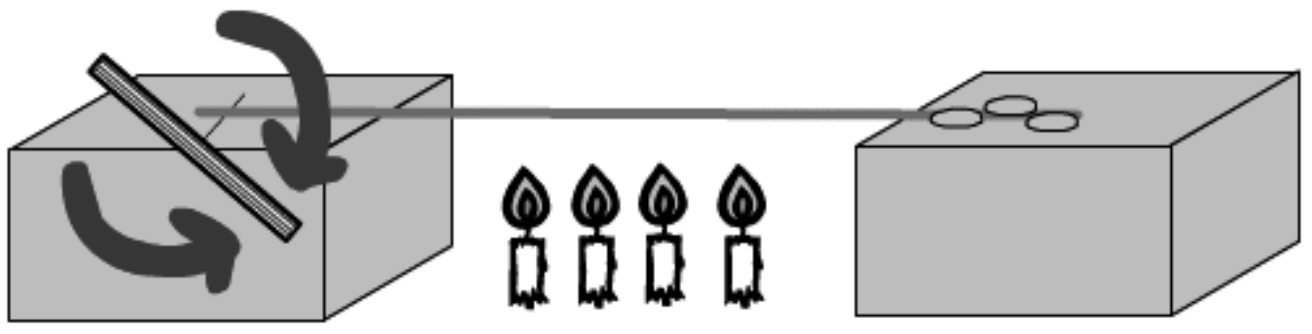
Nothing
Rotate to the left
Rotate to the right

Please make a PREDICTION: When I position four lit candles under the metal rod, what do you think will happen? Circle your prediction:
A) Nothing
B) The straw will rotate to the left (counterclockwise)
C) The straw will rotate to the right (clockwise)

Comment on WHY you think this will happen:

\section{AFTER THE DEMONSTRATION:}

Now that you observed what happened in the demonstration and we discussed why it happened, please explain in your own words what you learned: 
Appendix B: One-, Two-, and Three-month Post-assessment (PA1, PA2, PA3)

Think back to when we conducted the following demonstration in class:

As an experiment, a metal rod was placed between two blocks. One end was made to not move, and the other was attached to a needle and straw. If the metal rod was heated using candles, what will the straw do?

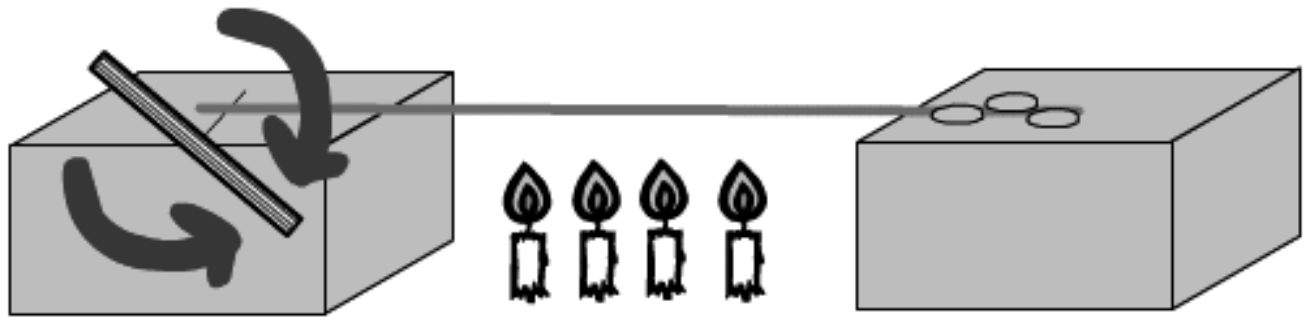
Nothing
Rotate to the left
Rotate to the right

In the space below, please describe what happened in the experiment and explain why it happened: 